\title{
Biological Sample Storage Condition Log
}

National Cancer Institute

\section{Source}

National Cancer Institute. Biological Sample Storage Condition Log. NCI Thesaurus. Code C115535.

Records of the data pertaining to monitoring and tracking of the storage condition of a biological sample. 